\title{
Políticas de avaliação e regulação da educação superior no Brasil
}

\author{
Sofia Lerche Vieira \& Jaana Flávia Fernandes \\ Nogueira
}

Resumo

Este artigo aprofunda a trajetória das políticas de avaliação e regulação da educação superior no Brasil, cuja gênese deve ser buscada em movimentos internos de regulação no país. Tal processo inicia-se ainda na década de 70 do século XX, quando são criadas as primeiras iniciativas de avaliação da pós-graduação em âmbito nacional, e tem continuidade ao longo do tempo. O texto aborda as iniciativas que se instauram gradativamente no período compreendido entre aquele momento histórico, as décadas subsequentes e os anos recentes, tomando como marco conclusivo o Plano Nacional de Educação, aprovado por lei em 2014. Com base nos momentos-chave desse percurso, identificados mediante análise documental, são consideradas distintas fases entre as origens, a organização e a consolidação da avaliação e regulação da educação superior no Brasil. Ao longo dessa trajetória são construídos os principais marcos do desenvolvimento do Estado Avaliador no Brasil, os quais são caracterizados por forte presença de um aparato técnico e burocrático que, pouco a pouco, imprime um novo desenho às políticas de educação superior que têm na regulação um forte componente de seu desenho atual.

Palavras-chave:

avaliação; educação superior; pós-graduação. 


\title{
Policies for evaluation and regulation of higher education in Brazil
}

\begin{abstract}
This article explores the trajectory of the policies of evaluation and regulation of higher education in Brazil, whose genesis must be sought in internal regulatory movements in the country. This process began in the 70's of the 20th century, when the first postgraduate evaluation initiatives were created at national level, and it continues over time. The text focuses on the processes that are gradually established in the period between that historical moment, the subsequent decades and recent years, taking as a conclusive landmark the National Education Plan, approved by law in 2014. Based on the key moments identified through documentary analysis, distinct phases between the origins, organization and consolidation of processes of evaluation and regulation of higher education in Brazil are considered. Throughout this trajectory, the main landmarks of the development of the Evaluating State in Brazil have been constructed, which are characterized by a strong technical and bureaucratic apparatus that, that little by little, prints a new design to the higher education policies that have in the regulation a strong-component of its present design.
\end{abstract}

Keywords: evaluation; college education; postgraduate studies.

\section{Políticas de evaluación y reglamentación de la educación superior en Brasil}

Resumen: Este artículo profundiza la trayectoria de las políticas de evaluación y reglamentación de la educación superior en Brasil, cuya génesis se debe buscar en movimientos internos de reglamentación en el país. Dicho proceso se inicia aún en los años 70 del siglo XX, cuando se crean las primeras iniciativas de evaluación del posgrado en el ámbito nacional, y sigue a lo largo del tiempo. El texto plantea los procesos que se instauran con gradación en el período comprendido entre aquel momento histórico, las décadas subsiguientes y los años recientes, considerando como hito conclusivo el Plan Nacional de Educación, aprobado por ley en 2014. Con base en los momentos clave de ese recorrido, identificados mediante análisis documental, se consideran distintas fases entre los orígenes, la organización y la consolidación de los procesos de evaluación y reglamentación de la educación superior en Brasil. A lo largo de esa trayectoria se construyen los principales marcos del desarrollo del Estado Evaluador en Brasil, los que se caracterizan por fuerte presencia de un aparato técnico y burocrático que, poco a poco, imprime un nuevo diseño a las políticas de educación superior que tienen, en la reglamentación, un fuerte componente contemporáneo.

Palabras clave: evaluación; educación superior; posgrado.

\section{Politiques d'évaluation et régulation de l'éducation supérieure au Brésil}

Résumé: Cet article approfondit la trajectoire des politiques d'évaluation et régulation de l'éducation supérieure au Brésil, dont la genèse doit être recherchée aux mouvements internes de régulation dans le pays. Tel procès commence encore dans les années 70 du XXe siècle, lorsque les premières initiatives d'évaluation des études postuniversitaires sont créées à l'échelle nationale, et sont continuées au cours du temps. Le texte discute les procès qui se sont établis progressivement dans la période entre ce moment historique, les décennies suivantes et les années recentes, en prenant comme tournant définitif le Plan National de l'Éducation, autorisé par loi en 2014. En fonction de moments clés de ce cours, identifiés à travers une analyse documentaire, on a consideré différentes phases entre les origines,organization et la consolidation des procès d'évaluation et régulation de l'éducation supérieure au Brésil. Au cours de cette trajectoire les principaux tournants du développement de l'État Évaluateur au Brési sont conçus. Ils sont caractérisés par une forte présence d'un appareil technique et bureaucratique qui, peu à peu, imprime une nouvelle conception aux politiques de l'éducation supérieure qui ont, au sein de la regulation, un fort élément contemporain.

Mots clés: évaluation; éducation supérieure; études post-universitaires. 


\section{Introdução}

As reformas antigas e recentes da educação superior no Brasil podem ser compreendidas à luz de diferentes «tempo(s)» e «movimento(s)» (Vieira \& Nogueira, 2017). Se na trajetória desse nível de ensino é possível identificar continuidades e rupturas entre os modelos de educação superior instituídos no país, nas últimas décadas é possível observar alguns fenômenos próprios, um dos quais é a forte presença de práticas de avaliação e regulação (Barroso, 2005; Maroy, 2011, Verhine, 2015; Vieira \& Vidal, 2016).

A avaliação pode ser compreendida como a coleta de informações sobre um determinado processo, com o objetivo de aperfeiçoá-lo. Enquanto política pública, refere-se a ações que visam dimensionar a qualidade do funcionamento de sistemas específicos, implicando em maior ou menor grau na busca de influência sobre resultados. Embora seja associada por muitos ao advento do neoliberalismo, as raízes de iniciativas de avaliação são anteriores às circunstâncias econômicas e políticas que propiciaram o surgimento de novas formas de controle do Estado sobre a oferta de serviços públicos educacionais. Em diversos contextos, particularmente nos países mais industrializados, a avaliação de sistemas educacionais tem sido uma prática comum pelo menos desde meados do século passado. Para citar apenas alguns casos emblemáticos, os Estados Unidos, a França e a Inglaterra gradativamente implementaram robustos sistemas de avaliação. A avaliação, com efeito, é parte intrínseca da ação governamental, representando para muitos autores elemento central do "ciclo de políticas» (Souza, 2006).

O conceito de regulação, por sua vez, possui diferentes significados conforme os contextos disciplinares e linguísticos, como bem discute Barroso (2005). Analisando a regulação como um modo de coordenação das redes de educação, o autor a define como um elemento constitutivo de qualquer sistema que "tem como principal função assegurar o equilíbrio, a coerência, mas também a transformação desse mesmo sistema" (Barroso, 2005, p. 733). Em sua visão, "o processo de regulação compreende não só a produção de regras (...) que orientam o funcionamento do sistema, mas também o (re)ajustamento da diversidade de ações dos atores em função dessas mesmas regras" (Barroso, 2005, p. 733).

Conforme observa Maroy (2011), a regulação é um ação institucional e política onde atuam diversos atores. Em suas palavras, " a regulação institucional remete, pois, aos modos de orientação, de coordenação e de controle dos atores, que são objetivados e institucionalizados em dispositivos materiais, legais, técnicos, que derivam de uma ação pública e de estado (aí compreendidos os dispositivos de "mercado")" (Maroy, 2011, p. 22). 
Contribuindo para a definição de orientação e controle dos atores, a regulação é procedimento construído simultaneamente de "cima para baixo» e de «baixo para cima» como condição de sobrevivência mesma dos próprios sistemas. Muito embora as atividades de avaliação e regulação sejam frequentemente associadas, "a literatura internacional revela a importância da divisão entre os dois temas. Tal divisão é imprescindível para dar ênfase ao fato de que a regulação é apenas uma entre as diversas consequências das ações avaliativas" (Verhine, 2015, p. 614).

No caso brasileiro, as primeiras iniciativas de avaliação da pós-graduação stricto sensu no país surgiram ainda nos anos 70 do século XX. Isto ocorreu sob a égide do regime militar e, portanto, muito antes da chegada das influências neoliberais e, quando se deu forte impulso à criação de cursos de pós-graduação. Tal perspectiva está em sintonia com o entendimento de que "o Estado Avaliador difere largamente em tipo, abrangência, impacto e propósito de sistema para sistema" (Neave, 2017, citado por Hsien \& Huisman, 2016). Nesse sentido, por óbvio que possa parecer, é oportuno reafirmar que a trajetória do Estado Avaliador varia de contexto para contexto, tendo características diferenciadas na Europa e em outros continentes.

O presente artigo focaliza a avaliação da educação superior no Brasil, buscando identificar as políticas construídas com tal finalidade, desde as primeiras iniciativas até o período mais recente. Está dividido em três tópicos. O primeiro trata das origens das políticas de avaliação da educação superior no Brasil até o final da década de 1980. O segundo trata da organização da avaliação no país, compreendendo o período de 1990 a 2002. O terceiro, por fim, aborda a fase de consolidação das políticas de avaliação e regulação da educação superior, entre 2003 e 2014.

\section{Primeiras iniciativas de avaliação (1976-1989)}

A matriz da concepção contemporânea de educação superior no Brasil deve ser buscada na reforma universitária de 1968, fonte de inspiração para ideias que passaram a orientar esse nível de ensino. Exemplos nesse sentido são o sistema de créditos, a matrícula por disciplinas, a estrutura departamental, a carreira universitária, a pós-graduação, entre outros. Outra ideia força foi o princípio da indissociabilidade entre ensino e pesquisa (Lei n. 5.540/1968, arts. $2^{\circ}$ e 11, c), ao qual posteriormente se agregou também a atividade de extensão (Constituição Federal, 1988, art. 207).

Se a reforma encaminhada em 1968 foi pródiga em temas que informariam o debate sobre educação superior desde então, o mesmo não pode ser dito sobre a avaliação. Naquele momento histórico específico, esta não era ainda uma questão desafio à formulação e implementação de políticas. Entretanto, poucos anos depois, começa a entrar em pauta, mais especificamente no âmbito da pós-graduação. 
A criação de cursos de pós-graduação foi fomentada no contexto de implantação da reforma de 1968. Assim, desde o início da década de 70 do século XX as instituições públicas foram estimuladas a criar cursos de mestrado e doutorado, até como resposta à exigência de titulação para a docência no nível superior. A primeira avaliação da pós-graduação ocorreu por iniciativa da Coordenação de Aperfeiçoamento de Pessoal de Nível Superior - Capes, em 1976 (CAPES, s. d.).

O processo então criado consistia em uma avaliação anual distinta para os cursos de mestrado e doutorado, cujos resultados eram traduzidos em cinco conceitos ( $A, B$, C, D e E, sendo A o mais elevado e E o mais baixo). Tais resultados eram considerados como «informação reservada», restrita ao âmbito das agências federais.

Essa iniciativa de avaliação foi objeto de gradativo aperfeiçoamento. Em 1980 foram incorporadas visitas de consultores externos aos cursos objeto de avaliação. Em 1982 a Capes passou a divulgar os resultados da avaliação para os próprios cursos e instituições. Um pouco depois, em 1983, essa mesma instituição passou a solicitar que os programas indicassem nomes de consultores das áreas específicas de conhecimento para compor listas de onde seriam escolhidos representantes de área. A partir de então os membros da comunidade científica passaram a ser responsáveis pela coordenação dos processos avaliativos em suas áreas de atuação no âmbito da pós-graduação (Capes, s. d.).

Em 1984 passou-se a adotar a periodicidade bienal para avaliação de cursos. No ano seguinte, os resultados da avaliação passaram a ser amplamente divulgados, sendo foco de publicações e debate no âmbito acadêmico.

É oportuno observar que, se a avaliação da pós-graduação ganhou corpo e substância no Brasil a partir de meados da década de 1970, e se fortaleceu no intervalo de tempo subsequente, o mesmo não ocorreu em relação à graduação, cujos processos de avaliação tiveram início muito mais tarde.

A análise do debate sobre a universidade nos anos 1980 permite perceber que as primeiras sementes da ideia de avaliação surgiram no início daquela década. Tal movimento pode ser detectado por uma reconstituição das idas e vindas de projetos de reforma(s) da reforma (de 1968) e de iniciativas que traziam o germe da avaliação (Vieira, 1990). Ilustrativa desta intenção foi o Programa de Avaliação da Reforma Universitária - Paru (1982).

O Paru foi uma iniciativa do Ministério da Educação, cujo grupo inicial de trabalho contou com representação de vários organismos do Estado, representantes do movimento docente e de servidores. Entre 1983 e 1986, o grupo produziu documentos e estudos diversos na perspectiva de uma avaliação da reforma universitária em um amplo conjunto de instituições (Vieira, 1990).

Ainda que os primeiros movimentos na direção da avaliação tenham surgido antes mesmo da retirada dos militares do poder, é sob os auspícios da grande e intensa 
mobilização política da primeira metade dos anos 1980 que este debate se amplia. Para tanto, contribui sobremaneira a emergência de um movimento docente organizado no contexto da transição democrática, bem como do protagonismo do Conselho de Reitores das Universidades Brasileiras (CRUB).

Em 1984, no contexto da mobilização nacional por eleições diretas (Diretas Já) e, mais tarde, durante a campanha, o candidato Tancredo Neves assumiu com o movimento docente o compromisso de encaminhar uma nova proposta de reforma das universidades federais. Em seu discurso de posse, lido pelo então vice-presidente José Sarney, o presidente eleito reiterava este compromisso, expressando seu plano de constituir uma comissão de alto nível para estudar a situação dessas instituições, bem como apresentar propostas para sua reforma. Mesmo com sua morte, a promessa foi mantida. Tendo sido criada em março de 1985, essa comissão apresentou ao ministro da Educação seu relatório final em novembro do mesmo ano. As considerações nele contidas eram um tanto genéricas e não avançavam propostas concretas para a crise das universidades federais. O Ministério da Educação, então, cria novo grupo de trabalho.

O Grupo Executivo para a Reformulação da Educação Superior - Geres foi instituído com o objetivo de propor medidas operacionais para a reformulação das instituições federais de ensino superior. Criado em 1986 e instalado no mesmo ano, este grupo apresentou um documento final em que foram apresentadas medidas diversas visando a autonomia das universidades públicas federais (Vieira, 1990).

O documento do Geres propôs uma articulação entre autonomia universitária e sua avaliação. Na perspectiva do documento, o referido sistema de avaliação utilizaria "amplamente a colaboração da comunidade acadêmica, através das Comissões de Especialistas de Ensino" (Geres, 1986, p. 9). Noutras palavras, o modelo inspirava-se nos procedimentos já adotados para a avaliação da pós-graduação. Para concretizar essas e outras medidas, o Geres apresentava um projeto de lei no qual estava prevista a avaliação da educação superior a ser feita pelo MEC.

No âmbito do MEC esse trabalho deveria ser conduzido pela Secretaria de Educação Superior - SESU e contemplar duas vertentes: "avaliação do desempenho institucional" e "avaliação da qualidade dos cursos oferecidos" (Geres, 1986, p. 20). Tal foi a controvérsia gerada em torno do Geres que suas propostas terminaram por não ter o andamento pretendido pelo Ministério.

Marcos significativos da retomada da democracia na segunda metade dos anos 80 do século XX foram a eleição e posse de uma Assembleia Nacional Constituinte e a consequente votação de uma nova Constituição. O capítulo da educação na nova Carta Magna traz dez artigos (arts. 205 a 214) e nenhum deles apresenta indicações sobre o tema. Este só aparecerá nas orientações da nova LDB, já no período em que a temática da avaliação ganha maior visibilidade, ultrapassando a esfera da pós-graduação e chegando à graduação e à educação básica. 


\section{Organização de políticas de avaliação (1990-2002)}

Em 1990, tem início nova administração presidencial com a ascensão de Fernando Collor de Melllo ao poder ${ }^{1}$. Sem um projeto consistente de ação política ou econômica, Collor deflagra uma série de iniciativas com o objetivo de reduzir a presença do Estado na vida pública. O amplo pacote de mudanças trazido com seu governo propõe uma reforma do Estado que, embora não avançasse significativamente, colocaria o debate sobre o tema em cena.

Importante iniciativa instituída no governo Itamar Franco foi a criação do Programa de Avaliação Institucional das Universidades Brasileiras - Paiub (1993), no âmbito do Ministério da Educação. A ideia subjacente ao Paiub seria oferecer uma resposta ao desafio de implantar um sistema de avaliação institucional também para a graduação, tendo em vista que a pós-graduação já possuía processos próprios de avaliação (Universia, 2002).

O Paiub se propunha a integrar os resultados das iniciativas de avaliação que estavam sendo implementadas pelo MEC. Na perspectiva desse programa, o processo de avaliação institucional seria composto de três etapas que se complementavam mutuamente: uma avaliação interna, "realizada pela instituição, com a participação de todas as instâncias e segmentos da comunidade universitária, considerando as diferentes dimensões de ensino, pesquisa, extensão e gestão"; uma avaliação externa feita "por comissão externa, a convite da IES, a partir da análise dos resultados da avaliação interna e de visitas à instituição, resultando na elaboração de um parecer"; uma reavaliação mediante a "consolidação dos resultados da avaliação interna (autoavaliação), da externa e da discussão com a comunidade acadêmica resultando na elaboração de um relatório final e de um plano de desenvolvimento institucional" (Universia, 2002, p. 1).

O governo subsequente, de Fernando Henrique Cardoso - FHC (01/01/1995 a 01/01/2003), levou adiante a reforma do Estado, iniciada na gestão anterior, propiciando condições para o avanço do Estado Avaliador. Entre as medidas para operacionalizar tal configuração, foi criado o Ministério da Administração Federal e Reforma do Estado (Mare).

Em geral, costuma-se associar as mudanças mais significativas empreendidas no âmbito legal pelo governo FHC no campo educacional à aprovação de uma LDB que tinha muito mais marcas do Executivo do que do próprio Legislativo ou da sociedade civil organizada.

É oportuno registrar, porém, que a criação de um novo aparato legal antecede a LDB, começando a se concretizar já no primeiro ano de governo, com a aprovação da Lei n. 9.131/95, que altera vários dispositivos da Lei n. 4.024/61, com destaque para o papel do Ministério da Educação (então também do Desporto) na formulação 
e avaliação da política nacional de educação. Passo importante nesse sentido é a criação do Conselho Nacional de Educação, órgão de colaboração ao governo federal.

Outra medida adiantada pela referida lei foi a instituição dos chamados exames nacionais com a finalidade de "aferir os conhecimentos e competências adquiridos pelos alunos em fase de conclusão dos cursos de graduação" (Lei n. 9.131/95, art. $\left.3^{\circ}\right)$. Registre-se ainda a referência de que o MEC faria uso "de procedimentos e critérios abrangentes dos diversos fatores que determinam a qualidade e a eficiência das atividades de ensino, pesquisa e extensão" (Idem).

Para Weber (2010, p. 1255), "essa lei respaldou a generalização, no país, de outra forma de avaliação, voltada para as instituições, mas o fez desconsiderando o processo de construção e execução do Paiub". A autora destaca, ainda, que os critérios de avaliação adotados passaram a atingir todas as instituições de educação superior e que, com isso, o MEC avocou a ação de coordenador da política educacional.

Ao assumir tal papel, o Ministério instituiu o Exame Nacional de Cursos, conhecido como Provão. O Provão inicialmente foi objeto de forte resistência pela comunidade acadêmica, sobretudo por parte dos estudantes, muitos dos quais organizavam os chamados boicotes ao exame. De todo modo, sua implementação teve continuidade e acabou por ser incorporado como prática de avaliação externa de cursos e instituições.

Complementando as orientações da Lei n. 9.131/95, o governo federal promulgou decreto prevendo que o processo de avaliação dos cursos e instituições de ensino superior compreenderia quatro procedimentos, a saber: 1) análise dos principais indicadores de desempenho global do sistema nacional de ensino superior; 2) avaliação do desempenho individual das instituições de ensino superior; 3) avaliação do ensino de graduação; e, por fim, 4) avaliação dos programas de mestrado e doutorado (Decreto n. 2.026/96, art. $1^{\circ}$, incisos I a IV).

Para concluir o aparato legal de sustentação do que, em momento posterior, seria identificado como Estado Avaliador, aprovou-se uma Emenda Constitucional n. 14, de 1996, e uma nova Lei de Diretrizes e Bases da Educação Nacional - LDB (Lei n. 9.394/1996). Na perspectiva da legislação aprovada, ganha corpo o papel da União como instância de avaliação e acreditação na distribuição das incumbências entre as unidades federativas. Cabe-lhe, em primeiro lugar, "a coordenação da política nacional de educação, articulando os diferentes níveis e sistemas e exercendo função normativa, redistributiva e supletiva em relação às demais instâncias educacionais" (LDB, art. $8^{\circ}, \S 1^{\circ}$ ).

A estas funções viriam somar-se novas incumbências definidas no art. $9^{\circ}$ da LDB. Dentre elas, cabe destacar a tarefa de "assegurar processo nacional de avaliação do rendimento escolar no ensino fundamental, médio e superior"; "assegurar processo nacional de avaliação das instituições de educação superior; e "autorizar, reconhecer, credenciar, supervisionar e avaliar, respectivamente, os cursos das instituições de educação superior e os estabelecimentos do seu sistema de ensino". 
Como se vê, a LDB atribuiu à União uma dupla função na coordenação da política nacional de educação no que se refere ao processo nacional de avaliação: de um lado, aferir o "rendimento escolar em todos os níveis de ensino" (LDB, art. 9, VI) e, de outro, promover a avaliação "das instituições de educação superior" (LDB, art. 9, VIII). Tais dispositivos abriram caminho para a criação de um aparato jurídico-normativo compatível com tarefa de tal envergadura.

Além da missão de coordenar a política nacional de avaliação e assegurar os processos nacionais de avaliação, ao Estado caberia ainda ampliar suas responsabilidades no que se refere às funções de acreditação. Assim, com a colaboração de um Conselho Nacional de Educação - CNE , com funções normativas e de supervisão, incumbir-se-ia da tarefa de "autorizar, reconhecer, credenciar, supervisionar e avaliar, respectivamente, os cursos das instituições de educação superior e os estabelecimentos do seu sistema de ensino" (LDB, art. 9, IX). Anos mais tarde, esta atribuição seria fortalecida, particularmente a partir da aprovação de novos instrumentos legais relativos à avaliação da educação superior, já no governo de Luiz Inácio Lula da Silva - Lula (01/01/2003 a 01/01/2011).

O caráter regulador do Estado avança com medidas diversas, estabelecendo procedimentos de avaliação do desempenho individual das instituições de ensino superior - IES, com apoio de especialistas na área de avaliação institucional. Segundo Weber (2010, p. 1256), tais iniciativas tinham como objetivo "desencadear processos de mudanças no interior das próprias IES, bem como subsidiar o estabelecimento de padrões de qualidade a serem por elas atingidos". Assim surge, em sua visão, a tensão entre avaliação e regulação na discussão sobre a qualidade da formação em nível superior.

Visto na perspectiva de hoje, o movimento percorrido pela graduação é um tanto mais lento que o da pós-graduação. Levaria um longo intervalo para se completar, iniciando-se no governo de Fernando Henrique Cardoso e completando-se nos governos Lula e Dilma². Além das medidas agilizadas por decretos e portarias do MEC, outras diriam respeito à acreditação, expressa em normatização ampla ao longo dos anos subsequentes do governo FHC.

Fazendo um balanço sobre a educação superior durante a gestão de Fernando Henrique Cardoso, Durham (1999, p. 250-251) afirmou que "se o governo federal pode ser criticado por não ter realizado ainda a reforma necessária no sistema de ensino superior público, houve iniciativas muito importantes na área da avaliação, que constitui um dos fundamentos para a futura reforma". A autora cita como exemplo a criação do Exame Nacional de Cursos. Chama a atenção, ainda, para o papel das comissões de especialistas no assessoramento ao governo na avaliação de cursos, através de visitas in loco. O governo de FHC, conforme a reconstituição da trajetória de algumas de suas políticas permite perceber, traz a questão da avaliação para o centro da educação. 


\section{Consolidação das políticas de avaliação (2003-2014)}

Logo no início do governo Lula, a educação superior retorna à pauta das prioridades do MEC. Já em meados de 2003 foi criada uma Comissão Especial de Avaliação - CEA, com a finalidade de "analisar, oferecer subsídios, fazer recomendações propor critérios e estratégias para a reformulação dos processos e políticas de avaliação da educação superior e elaborar a revisão crítica de seus instrumentos, metodologias e critérios utilizados" (Portaria MEC/SESu n 11 de 28 de abril de 2003). Dessa iniciativa resultou, nesse mesmo ano, uma proposta preliminar intitulada Sistema Nacional de Avaliação da Educação Superior (SINAES): base para uma nova proposta de avaliação da educação superior brasileira (Nogueira, 2006).

Em 2004, medidas diversas são adotadas no sentido de viabilizar a avaliação externa dos cursos de graduação. Dentre elas, cabe assinalar a criação do Sistema Nacional de Avaliação da Educação Superior - Sinaes; a instituição da Comissão Nacional de Avaliação da Educação Superior (Conaes), órgão colegiado de coordenação e supervisão do Sinaes, cuja nomeação é delegada à competência do Ministro da Educação; e a realização da primeira edição do Exame Nacional de Desempenho de Estudantes (Enade), em substituição ao Exame Nacional de Cursos ou Provão.

Tão logo é instituído o Sinaes, o governo federal torna pública a realização de credenciamento de profissionais especialistas para compor um Cadastro de Avaliadores ad hoc do Instituto Nacional de Estudos e Pesquisas Educacionais Anísio Teixeira - Inep. Para viabilizar tal iniciativa é instituída uma Taxa de Avaliação in loco das instituições de educação superior e dos cursos de graduação. O cadastro para compor o Banco de Avaliadores Institucionais do Inep é também objeto de providências específicas.

Paralelamente à operacionalização de medidas de avaliação por pares, o governo federal agiliza providências no sentido de que a Secretaria de Educação Superior (SESu) do MEC assuma a responsabilidade pela regulação do Sistema Federal de Ensino Superior. No âmbito do ensino profissional de nível tecnológico essa supervisão e regulação passam a ser exercidas pela Secretaria de Educação Média e Tecnológica, compreendendo o credenciamento e o recredenciamento dos Centros de Educação Tecnológica, e autorização, reconhecimento e renovação de reconhecimento de cursos superiores de tecnologia, nas modalidades presencial e a distância.

Outra medida adotada é a instituição de um modelo de gestão visando propiciar "a administração integrada e resolutiva dos processos de avaliação e regulação das instituições e dos cursos de educação superior do Sistema Federal de Ensino Superior" (Portaria n. 3.643, de 9 de novembro de 2004).

No apagar das luzes de 2004, um pacote de cinco portarias encaminha novas providências visando fortalecer a presença e o poder do Estado no cenário da educação 
superior brasileira, que variam desde a seleção de cursos que deverão ser submetidos a verificação in loco, a processos de reconhecimento, credenciamento e recredenciamento, dentre outros.

Depois do movimentado ano de 2004, quando se cria o Sinaes e são instituídas outras formas de intervenção que ampliam a presença do Estado na avaliação, outros instrumentos normativos são concebidos e iniciativas de avaliação dos sistemas de ensino se materializam. Isto ocorre não apenas na educação superior, objeto da presente reflexão, como também na educação básica.

O movimento de regulação prossegue entre 2005 e 2012, quando são produzidas resoluções, portarias e decretos diversos. Configura-se, assim, um ambiente propício à expansão de um aparato burocrático e normativo para assegurar tal crescimento. Do lado da academia, depois de um estranhamento e rejeição ao protagonismo do Estado nos governos anteriores, uma acomodação de forças contribui para seu fortalecimento. Tal movimento é facilitado pelo recrutamento de quadros técnico-políticos para compor a burocracia estatal e pelo prestígio conferido às comissões de especialistas reconhecidas pela comunidade científica. Nesse contexto é simples compreender como, pouco a pouco, de tendência dominada a avaliação passa a dominante. Questionamentos persistem, é fato, mas o tempo abranda a contundência anterior. As práticas de avaliação de cursos, por sua vez, avançam e se disseminam para o conjunto das IES.

Antes de passar às considerações finais, é oportuno registrar mais dois marcos no fortalecimento e consolidação da presença do Estado na avaliação. O primeiro é a criação de um órgão do MEC, a Secretaria de Regulação e Supervisão da Educação Superior - Seres, para responder pela regulação e supervisão das IES. O segundo refere-se ao envio ao Congresso Nacional de projeto de criação de um órgão externo de regulação.

Com o objetivo de "induzir a elevação da qualidade do ensino por meio do estabelecimento de diretrizes para a expansão de cursos e instituições, de conformidade às diretrizes curriculares nacionais e de parâmetros de qualidade de cursos e instituições", a Seres foi criada em 2011 (Decreto n. 7.480/11) e suas atribuições definidas posteriormente (Decreto n. 7.690/12, com as alterações do Decreto n. 8.066/13). Sua tarefa seria assumir encargos relativos à regulação e supervisão de Instituições de Educação Superior (IES), públicas e privadas, e cursos superiores de graduação do tipo bacharelado, licenciatura e tecnológico, e de pós-graduação lato sensu, todos na modalidade presencial ou a distância. Absorveu, assim, responsabilidades antes desenvolvidas por outras secretarias (SESu, Setec e Seed) do MEC.

A segunda medida reveladora da consolidação da presença do Estado na avaliação articula-se à intenção do governo federal de criar o Instituto Nacional de Supervisão e Avaliação da Educação Superior (Insaes), agência reguladora deste nível de ensino no 
país. Após ser protocolado, o Projeto de Lei n. 4.372/2012 passou a tramitar no Legislativo. Como ocorreu com outros projetos, entretanto, sua aprovação não foi objeto de consenso, concluindo-se, assim, o governo de Dilma Rousseff sem maiores avanços em relação à matéria, situação que persistiu na gestão que veio a sucedê-la.

Se a proposta de criar essa agência reguladora da educação superior não avançou até o final do primeiro governo Dilma, é oportuno lembrar que outras iniciativas, resultantes de processos construídos em maior diálogo com a sociedade civil, tiveram caminho distinto. É o caso do Plano Nacional de Educação (PNE), aprovado sob a forma de lei (Lei n. 13.005/14), depois de alguns anos de idas e vindas entre as duas casas legislativas do Congresso.

A análise do PNE permite perceber uma visão consolidada de Estado Avaliador e onipresente, sob cuja responsabilidade está o controle das políticas públicas de educação no país. Tal concepção é visível no corpo do texto como um todo, atravessado do início ao final por diretrizes, metas e estratégias cujos controles são de competência do Estado.

\section{Considerações finais}

Este estudo permitiu constatar o gradativo e contínuo avanço de mecanismos de controle sobre a educação superior no país. Tal processo se inicia ainda no regime militar com a introdução de mecanismos de avaliação dos cursos de pós-graduação, avançando na direção da graduação muito mais tarde, já a partir do governo Fernando Henrique Cardoso. Tais iniciativas ganham força e substância nos dois governos Lula e primeiro governo Dilma, intervalo sobre o qual se detém a análise.

Vale ressaltar que os mecanismos de avaliação e regulação da educação superior, frequentemente associados e tomados como semelhantes, possuem natureza distinta. De um lado, é importante reconhecer que a avaliação produz dados que servem para alimentar a regulação governamental. De outro, a literatura aponta a relevância de divisão desses dois temas. Enquanto a avaliação deve ser um processo mais amplo, com objetivo formativo, a regulação deve ser compreendida como uma parte necessária desse processo. Em síntese, enquanto a avaliação pode ser compreendida como uma política de Estado, a regulação deve ser tomada como uma política de governo (Verhine, 2015).

É interessante observar dois aspectos a respeito do processo de avaliação e regulação da educação superior no Brasil, vividos nos três períodos analisados. O primeiro é que inicialmente os resultados das avaliações tinham acesso restrito e, ao longo do tempo, foram sendo compartilhados, até que passassem a ser fortemente disseminados no país. O segundo é que os movimentos de resistência aos processos de avaliação e regulação nacional, observados com intensidade ao longo da década de 1990, 
foram sendo paulatinamente arrefecidos. Atualmente, parece haver uma aceitação dos mecanismos instituídos pelo governo federal, e, mais que isso, uma adequação das instituições de educação superior a tais mecanismos.

O alargamento do escopo das avaliações e o aumento do grau de complexidade que elas vêm adquirindo nos últimos anos podem representar o início de uma nova fase de políticas de avaliação. A visão sistêmica que as mesmas vêm tentando organizar e o refinamento dos dados, por meio de análises estatísticas multivariáveis, têm permitido que, cada vez mais, seus resultados sirvam como instrumentos de gestão para aqueles que atuam na governança e orientem tomadas de decisão sobre aplicação de recursos, delimitação de financiamentos, e estabelecimentos de metas.

\section{Notas}

1 Fernando Collor de Mello (Collor) foi presidente da república de 15 de março de 1990 a 29 de dezembro de 1992. Seu mandato foi encerrado por renúncia, decorrente de processo de impeachment movido pelo Congresso Nacional. Com sua saída assumiu o vice-presidente Itamar Franco, que governou o país de 29 de dezembro de 1992 a 01 de janeiro de 1995.

2 Dilma Rousseff governou o país de 01/01/2011 a 31/08/2016, quando foi afastada por processo de impeachment. O mandato para o qual foi eleita foi completado pelo vice-presidente Michel Temer, que exerceu a presidência de 31/08/2016 a 01/01/2019.

\section{Referências}

Barroso, J. (2005). O estado, a educação e a regulação das políticas públicas. Educação \& Sociedade, 26 (92), 725-751 [Disponível em http://www.scielo.br/pdf/es/v26n92/v26n92 a02.pdf, consultado em 12/09/2014].

Capes (s.d.). Evolução do sistema de avaliação da pós-graduação [Disponível em http://capes.gov.br/ images/stories/download/avaliacao/avaliacao-n/evolucao-da-avaliacao-enviado-ed-26fev.pdf, consultado em 12/09/2014]

Durham, E. R. (1999). A educação no governo de Fernando Henrique Cardoso. Tempo Social, 11 (2), 231-254.

Geres (1968). Relatório do Grupo Executivo para a Reformulação da Educação Superior [Disponível em http://www.schwartzman.org.br/simon/pdf/geres.pdf, consultado em 30/09/2014].

Marroy, C. (2011). Em direção a uma regulação pós-burocrática dos sistemas de ensino na Europa? In D. A. Oliveira \& A. Duarte (Org.). Políticas públicas e educação: regulação e conhecimento (pp. 1946). Belo Horizonte: Fino Traço.

Neave, G. (2018). Evaluative state, nation-state: a last hurrah? Revista Lusófona de Educação, 38, 11 21.

Souza, C. (2006). Políticas públicas: uma revisão da literatura. Sociologias, 8 (16), 20-45.

Universia (2012). Programa de Avaliação Institucional (PAIUB) [Disponível em http://noticias.universia. com.br/destaque/noticia/2002/02/08/552760/rograma-avaliao-institucional-(paiub).html\#, consultado em 24/03/2018]. 
Verhine, R. (2015). Avaliação e regulação da educação superior: uma análise a partir dos primeiros 10 anos do SINAES. Avaliação, 20 (3), 603-619.

Vieira, S. L. (1990). Universidade federal nos anos 80: o jogo da política educacional. Tese de doutoramento. São Paulo: Pontifícia Universidade Católica de São Paulo.

Vieira, S. L. Vidal, E. M. (2016). Estado Avaliador e educação superior no Brasil. Revista Educação Brasileira, 38, 77-112.

Vieira, S. L. Nogueira, J. F. F. (2017). Reformas da educação superior no Brasil: tempo(s) e movimento(s). Revista Lusófona de Educação, 35, 13-28 [Disponível em https://revistas.ulusofona.pt/index.php/ rleducacao/issue/view/701, consultado em 24/03/2018].

Weber, S. (2010). Avaliação e regulação da educação superior: conquistas e impasses. Educação e Sociedade, 31 (113), 1247-1269.

Sofia Lerche Vieira

Doutora em Educação pela Pontifícia Universidade Católica de São Paulo

(PUC/SP). Pesquisadora do Conselho Nacional de Desenvolvimento

Científico e Tecnológico (CNPq) e Pesquisadora Sênior no Centro de

Desenvolvimento da Gestão Pública e Políticas Educacionais da Fundação

Getulio Vargas (FGV), no Rio de Janeiro.

E-mail: sofialerche@gmail.com

ORCID: http://orcid.org/0000-0002-0271-6876

Jaana Flávia Fernandes Nogueira

Doutora em Educação pela Universidade da Califórnia, Los Angeles (UCLA)

Técnica em Assunto Educacionais do Ministério da Educação (MEC), atualmente licenciada. Coordenadora no Centro de Desenvolvimento da Gestão Pública e Políticas Educacionais da Fundação Getulio Vargas (FGV), no Rio de Janeiro.

E-mail: jaanafernandes@gmail.com

ORCID: http://orcid.org/0000-0001-5039-2645

Correspondência

Sofia Lerche Vieira

Rua Silva Paulet, 354 - Meireles, Fortaleza - CE. Brasil

CEP. 60.120-020

Data de submissão: Março 2019

Data de avaliação: Junho 2019

Data de publicçao: Dezembro 2019 